\title{
AC 2012-2979: CRITICAL THINKING: A PEDAGOGICAL INSTRUMENT FOR NEW ENGINEERING AND SCIENCE EDUCATORS
}

Dr. Robert M. Brooks, Temple University

Robert Brooks is an Associate Professor of civil engineering at Temple University. He is a Fellow of ASCE. His research interests are engineering education, civil engineering materials, and transportation engineering.

\section{Jyothsna K. S.,}

Jyothsna K. S., Department of English, St. Joseph's College, Bangalore, secured a Gold Medal for the highest aggregate marks in the Post Graduate English Literature course at St. Joseph's College (autonomous). K. S. has been working for the Department of English, St. Joseph's College for almost two years now, teaching both undergraduate and Postgraduate courses in English. K. S. published papers in intramural and extramural publications and presented papers at several conventions, conferences, and seminars.

\section{Mehmet Cetin, Temple University}

Mehmet Cetin is a doctorate candidate of civil engineering at Temple University. He has master's degree. His research interests are engineering education, civil engineering materials, and transportation engineering. 


\section{A reviewer commented on the draft}

\section{Comment}

The paper focuses a large percentage of the paper on the introduction/motivation/definitions/objectives/etc. and much less on the results. The paper presents results which they state are statistically significant, but when looking at the data, no explanation was given for how the control group surveys were conducted. In fact, the results indicate that the control groups in both surveys had the same base values in all categories. I don't understand how this could be the case. Please tell the reader the strategies behind making the surveys, collecting the data and analyzing the data collected. Revise the paper to include more results and less background information.

\section{Response}

The focus of the control group was not on the performance indices which are the components of the critical thinking. Therefore, in the draft paper, the average values were reported as the base values for all the categories in both surveys of the control groups. Upon reading the reviewer's comment the authors agree that the exact values should be reported and hence the exact values are given as shown in Tables 4 and 5.

Paper is revised by including more results and explanation and less background information. The following are some examples.

(1) Exact values are reported for all the 7 categories of the performance indices on the control groups as explained above.

(2) 7 critical thinking issues were removed from the background information, and

(3) Table 3 (consisting several examples of critical thinking questions connected to the activities showing the various components of the critical thinking issues) was added.

The strategies behind making the surveys, collecting the data and analyzing the data collected are shown in the survey instruments and modified Tables 4-5. The survey instruments with instructions to complete it are shown in Table 1 and 2.

A reviewer commented on the draft This is a critically thought out paper about critical thinking in the classroom. It is well written and should be of interest to the new engineering educators community.

\section{Response}

Thank you. 
A reviewer commented on the draft While this paper discusses critical thinking, an important skills for engineering educators and students alike, there are many problems with this paper draft which make it unacceptable.

The paper has little substance. A general argument for the importance of critical thinking as a life skill is presented, but the second paragraph of the "Why is critical thinking important" subsection is ineffective and unnecessary for making this point. The paper relies heavily on outside sources, including a Wikipedia article, (an) unspecified article(s) from roguecom.com, and example problems from a textbook. Scholarly articles or conference proceedings should be used as references instead. The paper does not specify whether or not the authors or publishers of the Botkin and Keller text granted permission for the inclusion of eight problem statements from that book, only two of which are directly discussed in the article.

\section{Response}

The second paragraph of the "Why is critical thinking important" subsection is removed. Reference to the Wikipedia article and unspecified article from rouguecom.com are removed. Only scholarly articles or conference proceedings were used as references. 8 critical thinking issues were removed from the background information and Table 3 was added. Table 3 consists of several examples of critical thinking questions connected to the activities showing the various components of the critical thinking issues.

Bibliography 8 is the text book referred in this paper. The authors, Daniel Botkin and Edward Keller and the publisher, John Wiley, Inc. of the text book are duly acknowledged at the end of the text of the paper. The text book is the only official text book of the course, "The environment" taught by the principal author and the new educators.

Since the paper is thoroughly reorganized by removing all the critical thinking issues (consisting of 8 pages), acknowledgement is provided at the end of the paper in addition to proper references in text of the paper (to the authors and editor of the book), the paper is not used for commercial purpose, the paper is used only for research purpose and consideration for publication in the ASEE conference which is a professional conference, no further permission from the editor or the authors is needed.

\section{Comment}

While results are presented in tabular form from the pre- and post-intervention data, the survey instrument itself is not shown, nor is the protocol for the collection of this data described.

\section{Response}

The survey instruments with instructions (and protocol) to complete it are shown in Table 1 and 2 . 


\section{Comment}

This is an interesting topic, but it is not ready for publication at this time.

\section{Response}

With all the changes consisting of positive and constructive response to each of the reviewers' comments the authors of the paper sincerely believe that the paper is ready for consideration for publication.

\section{Comment}

It seems curious that the ratings on the base values for each of the seven critical thinking criteria have precisely the same values for the educators self evaluation $(79 \%)$ and the students evaluation (72\%). There should be an explanation of this. There are also spelling and grammar issues in the paper.

\section{Response}

See the response for the previous reviewer's comment. The focus of the control group was not on the performance indices which are the components of the critical thinking. Therefore, in the draft paper, for the reason of simplicity, the average values were reported (even though exact values were available) as the base values for all the categories in both surveys of the control groups. Upon reading the reviewer's comment the authors agree that the exact values should be reported and hence the exact values are given as shown in Table 4 and 5. The spelling and grammar issues were corrected.

\section{Conclusion}

The paper was thoroughly reorganized. All the comments of the reviewers were positively and constructively implemented. Significant amount of background information was removed. New tables and section(s) were added. With all these modifications the authors believe that the paper is suitable for consideration for publication at the conference. 


\title{
CRITICAL THINKING, A PEDAGOGICAL INSTRUMENT FOR NEW ENGINEERING AND SCIENCE EDUCATORS
}

\begin{abstract}
The objective of this study is to encourage new engineering and science educators to use critical thinking as a pedagogical instrument. The scope of the paper is limited to new educators' teaching effectiveness. Several examples of critical thinking assignments are described in the paper.

Two confidential surveys were conducted. The first one was a self evaluation of new educators' effectiveness as teachers. The surveys were administered before and after use of the pedagogical instrument. The pre-application and post-application scores showed an average rating of $79 \%$ and $92 \%$ respectively. The use of the pedagogical instrument improved the scores by $17 \%$. The second confidential survey was a student evaluation of the new educators' teaching effectiveness. Before implementing the strategy, the average evaluation score was $72 \%$. The average rose to $87 \%$ after the strategy was implemented. The use of the pedagogical instrument improved the scores by $21 \%$. Both the improvements were statistically significant at an alpha value of 0.05 with calculated $t$ values of 2.9 and 3.1 respectively.
\end{abstract}

\section{Introduction}

According to Summer, et. al. critical thinking is understood as "a way of accurately dealing with the problems of life" ${ }^{1}$. Critical thinking is thinking about thinking ${ }^{2}$. It is contemplative thinking used in deciding what to believe or $\mathrm{do}^{3}$. More specifically, it is the process of actively and skillfully conceptualizing, synthesizing, analyzing, applying, and/or evaluating information ${ }^{4}$. Facione described it as the process of purposeful and self-regulatory judgment. The process involves reasoned consideration to various components of critical thinking such as context, evidence, and criteria" ${ }^{5}$.

For the past 2,500 years individuals have been using the Socratic method for promoting critical thinking. The method consists of probing questions to obtain clarity and logical consistency. The list of core critical thinking skills includes observation, interpretation, analysis, inference, evaluation, explanation, and meta-cognition ${ }^{6}$. Students can apply these skills to reading, writing, speaking, and listening. Critical thinking is important for becoming an excellent writer or reader.

\section{Why is critical thinking important?}

Critical thinking is an important element in all professional fields and academic disciplines. Understanding the importance of critical thinking in academics depends on understanding the significance of critical thinking in learning. 


\section{Objective}

The objective of this study is to evaluate the use of critical thinking as a pedagogical instrument by new engineering and science educators. The scope of the paper is limited to new educators' teaching effectiveness.

\section{Motivation}

Critical thinking is an important component of all academic fields and most professions. As students progress through university the importance of utilizing critical thinking increases. Yet many courses do not use critical thinking as a pedagogical instrument.

A study conducted by the Education Resources Information Center ${ }^{7}$ stated that higher education was failing to meet society's requirements for well-educated citizens. The study found that faculty might wish to develop students' thinking skills, but, in reality, they focus on discipline based concepts and facts at the lowest cognitive level at the cost of developing intellect or values based on critical thinking.

The importance and underuse of critical thinking provided the authors with strong motivation to pursue this study.

\section{Methodology}

For the purpose of the study, the following are chosen as the core components of critical thinking: 1) Observation, 2) Interpretation, 3) Analysis, 4) Inference, 5) Evaluation, 6) Explanation and 7) Meta-cognition.

An example of a critical thinking ${ }^{8}$ assignment is shown in the paper (Appendix 1). Nine new engineering and science educators were trained on the seven components of critical thinking described in this paper. Two confidential surveys were conducted. The first one consisted of the new educators' self evaluations of their effectiveness as teachers as shown in Table 1. The surveys were administered before and after use of the pedagogical instrument. The second confidential survey asked students to evaluate the new educators' teaching effectiveness as shown in Table 2. Table 3 contains several examples of critical thinking questions used in the activities showing the core components of critical thinking.

\section{Observation}

Attention plays an important part in observation. Students are encouraged to look at details because this is an important skill in all professions. Observation equips us with the material necessary for thought, reflection and judgment. Observation is influenced by experience, knowledge and emotion.

Students are encouraged to observe underlying values and beliefs. They are asked to distinguish between what is right and wrong and what is important and trivial. We typically prioritize values when making decisions. Our values influence the observations we make and the inferences we 
draw based on those observations as well as the decisions we make. It is important to note that values influence a speaker's or writer's choice of evidence presented and arguments made ${ }^{6}$.

\section{Interpretation}

Although the way we interpret and evaluate information is based on our cultural and societal backgrounds, each person, despite shared backgrounds, has his or her own unique interpretation of the world. In this section students are encouraged to become aware of the ways their own experiences, biases, beliefs, and values might influence their interpretations ${ }^{6}$.

\section{Analysis}

Students are asked how they come up with ideas, how their ideas relate to and interconnect with other ideas. Students are encouraged to discover assumptions and biases in order to uncover evidence. While assumptions can be declared (explicit) or implied (implicit) it is important to note that most assumptions are implicit ${ }^{6}$.

\section{Inference}

Inference is the interpretation of facts. The purpose of inferences is to evaluate conditions and make meaningful predictions. Students are expected to develop inferences based on both current observations and previous experience. While doing so they should obtain not only sufficient but also relevant evidence ${ }^{6}$. Students are reminded that inferences do not express certainty. They only indicate probability.

The new engineering and science educators are urged to seek improvement in the student's individual capacity by bringing greater reflection and deliberation to decision making.

\section{Evaluation}

Critical thinkers must also evaluate information by looking at the source, context and time of the information. Evaluating the source includes looking at credibility and bias. Students are expected to check the circumstances under which the source obtained the information ${ }^{6}$. Students are encouraged to ask what, where, why, when, and how.

Evaluation represents the empowerment of the student over the thought. The purpose of evaluation is to help the student decide whether he or she ought to agree or disagree with the information, or whether he or she ought to take or refrain from taking action 9 .

\section{Explanation}

Students are told to go beyond describing the concepts. They are expected to explain how and why they arrived at a particular answer(s). Their explanations should not only include identification of the causes but also indicate the students' knowledge, efficacy and expressiveness. Under this section students are expected to understand the issue. They are asked to grade the information presented ${ }^{9}$. 


\section{Meta-cognition}

Metacognition refers to one's knowledge of one's own cognitive processes, in other words, cognition about cognition. For example, if a student notices that he or she is having more trouble learning $\mathrm{X}$ than $\mathrm{Y}$ and if it strikes him or her that he or she should double check $\mathrm{Z}$ before accepting as a fact, then the student's metacognition skills are good. Metacognition is the most important skill in the critical thinking process. Unfortunately many students lack this skill. Two specific and detailed examples depicting the skill are given below. Both examples are taken from Botkin's ${ }^{8}$ book for the course "The Environment", a core course for non-science and nonengineering majors.

Example $1^{8}$ : In the Critical Thinking Issues of Phosphorus and Nitrogen cycles most of the students correctly answered critical thinking questions on each cycle independently. However, when a critical thinking question was asked on development of a diagram to illustrate the links between the phosphorus, nitrogen, and carbon cycles, a majority of the students earned significantly lower scores. This is due to a metacognition problem related to the integration of questions which were already answered.

Example $2^{8}$ : Consider the following Question No. 3 from the Critical Thinking Issue, "Energy Saved by Eating Lower on the Food Chain".

Here, students had metacognition problems in simultaneously dealing with the figures, completing the exercise, and using the mixed units (Kilograms, grams, $\%$, and kilojoules). Many students had problems determining which information was important for solving the problem and which information was irrelevant (the red herring).

Question: $1 \mathrm{~g}$ of completely dried vegetation contains 21 kilojoules $(\mathrm{kJ})$ of energy. Note that wheat has $78 \%$ water. What is the energy content of the 700, $000 \mathrm{lbs}$. of wheat ${ }^{8}$ shown in Appendix 1? Express the energy content in Joules.

Only $5 \%$ of the class obtained the correct answer of 1.4 trillion joules using the calculation shown below.

21 (KiloJoules/gram)* [(100-78)/100]* 700,000 (lbs) *0.455 lb/Kg. 1000 (g/Kg) =1.47 Trillion Joules.

In this question, the food chain details given in the Appendix 1 are red herrings.

\section{What Is New?}

The following two aspects are new. (1) As mentioned in the methodology section, the new engineering and science educators were trained on various components of critical thinking. (2) The educators taught the students to use a feedback method that reinforced the effectiveness of applying the critical thinking process in their learning. The output of Observation was fed into Interpretation. The output of Interpretation was fed into Analysis. The output of Analysis was fed into Inference. The output of Inference was fed into Evaluation. The output of Evaluation was 
fed into Explanation. The output of Explanation was fed into Observation. The cyclic feedback process was continued until all the elements of the critical thinking process are compatible and coherent. Meta-cognition was used as a check at every stage.

\section{Results and Discussion}

In the first survey, the pre-application and post-application scores showed an average rating of $79 \%$ and 92\%respectively. The use of the pedagogical instrument (shown in Table 1) improved the scores by $17 \%$. In the second survey, before implementing the strategy, the average evaluation score was $72 \%$. The average score rose to $87 \%$ after the strategy was implemented. The use of the pedagogical instrument (shown in Table 2) improved the scores by $21 \%$. Both the improvements were statistically significant at an alpha value of 0.05 with calculated $t$ values of 2.9 and 3.1 respectively as shown in Tables 4 and 5.

During informal discussions the new educators stated that, since they were relatively inexperienced (average 1.4 years teaching) and had previously used traditional lecture methods, the improvements could be attributed to the innovative strategy. Prior to this study their teaching consisted primarily of monotonous lectures with frequent writing on the black board where they turned their backs to the students. However, the authors acknowledge that the improvements could be attributed, at least in small part, to the new educators' teaching experience.

Since most students learn by observation, the new educators and the students ranked observation the highest among the seven components of critical thinking. The new educators stated that it was relatively easy to teach the importance of observation to students and that is why they ranked observation 97\% (Table 4) while teaching the Critical Thinking Group. Students ranked the new educators at $92 \%$ on observation (Table 5).

Since meta-cognition was the hardest to teach and learn, both groups ranked it last among the components of the critical thinking process. The new educators and students of the critical thinking group ranked it $85 \%$ and $79 \%$ respectively as shown in Table 4 and 5 respectively.

\section{Acknowledgement}

The textbook Environmental Science by Daniel Botkin and Edward Keller and published by John Wiley, Inc. is used in the course, "The environment" taught by the principal author and the new educators.

\section{Conclusion(s)}

In this paper critical thinking was used as a pedagogical instrument for improving new engineering and science educators' teaching effectiveness.

Over the next four years, the authors plan to implement this strategy with more new educators. The method presented in this study may be used at other institutions with appropriate modifications in order to help new educators improve their teaching effectiveness. 


\section{Bibliography}

1. Sumner, William (1906). Folkways: A Study of the Sociological Importance of Usages, Manners, Customs, Mores, and Morals. New York: Ginn and Co.. p. 633.

2. Raiskums, B.W., An Analysis of the Concept Criticality in Adult Education (2008)

3. Ennis, R.H., "Critical Thinking Assessment" in Fasko, Critical Thinking and Reasoning: Current Research, Theory, and Practice (2003). ISBN 978-1572734609

4. Scriven, M., and Paul, R.W., Critical Thinking as Defined by the National Council for Excellence in Critical Thinking (1987)

5. Facione, Peter A. Critical Thinking: What It is and Why It Counts, Insightassessment.com

6. Black H., and Black S. Building Thinking Skills, Book 2: Critical Thinking Skills for Reading, Writing, Math, and Science.

7. Lion Gardiner, Redesigning Higher Education: Producing Dramatic Gains in Student Learning, in conjunction with: ERIC Clearinghouse on Higher Education, 1995

8. Botkin, D., and Keller, E.,(2011) "Environmental Science," 8th Edition. John Wiley \& Sons,

9. Iran , T. Teaching the Critical Thinking Skill of Explanation. Department of Agricultural Education and Communication, University of Florida, http://aec.ifas.ufl.edu/abrams/step/explanation.pdf 


\section{Table 1. Pedagogical Instrument for New Educators' Self Evaluation}

Dear new educator,

Please make a self evaluation on the following seven performance indices that consist of the components of critical thinking. Grade each performance objectively on a scale of 0-100.

\begin{tabular}{|c|c|c|}
\hline Performance Index no & Performance Index & Grade \\
\hline 1 & Observation & \\
\hline 2 & Interpretation & \\
\hline 3 & Analysis & \\
\hline 4 & Inference & \\
\hline 5 & Evaluation & \\
\hline 6 & Explanation & \\
\hline 7 & Meta-cognition & \\
\hline
\end{tabular}


Table 2. Pedagogical Instrument for Student Evaluation on the New Educators' Teaching Effectiveness

Dear student,

Please make an evaluation on the new educators' teaching effectiveness on the following seven performance indices that consist of the components of critical thinking. Grade each performance objectively on a scale of $0-100$.

\begin{tabular}{|c|c|c|}
\hline Performance Index no & Performance Index & Grade \\
\hline 1 & Observation & \\
\hline 2 & Interpretation & \\
\hline 3 & Analysis & \\
\hline 4 & Inference & \\
\hline 5 & Evaluation & \\
\hline 6 & Explanation & \\
\hline 7 & Meta-cognition & \\
\hline
\end{tabular}


Table 3. Examples of critical thinking questions connected to the activities showing the various components of the critical thinking issues ${ }^{8}$

\begin{tabular}{|c|c|c|}
\hline Critical Thinking Issue & Question & $\begin{array}{c}\text { Activity showing } \\
\text { the component of } \\
\text { the Critical } \\
\text { Thinking Issue }\end{array}$ \\
\hline $\begin{array}{c}\text { How we can evaluate } \\
\text { constructed eco } \\
\text { systems }\end{array}$ & $\begin{array}{c}\text { Prepare a flowchart or sketch of the food web in a } \\
\text { marsh connecting the relationship between } \\
\text { cordgrass, nitrogen, chapter rail, and } \\
\text { invertebrates. }\end{array}$ & Observation \\
\hline $\begin{array}{c}\text { Is lead in the urban } \\
\text { environment } \\
\text { contributing to } \\
\text { antisocial behavior }\end{array}$ & $\begin{array}{c}\text { Propose theories to explain antisocial behavior in } \\
\text { urban environments other than lead's } \\
\text { contribution. }\end{array}$ & Interpretation \\
$\begin{array}{c}\text { Can tropical forests } \\
\text { survive in bits and } \\
\text { pieces }\end{array}$ & $\begin{array}{c}\text { Prepare a plan allowing approximately one third } \\
\text { of the Brazilian rain forest removed, and the rest } \\
\text { established as a national park. In your analysis, } \\
\text { take into account conservation of biological } \\
\text { diversity and the needs of local people to make a } \\
\text { living. }\end{array}$ & Analysis \\
\hline $\begin{array}{c}\text { Polar bears and the } \\
\text { reasons people value } \\
\text { biodiversity }\end{array}$ & $\begin{array}{c}\text { As a top predator, is the polar bear a necessary } \\
\text { part of its ecosystem? In making your inference, } \\
\text { consider the polar bear's ecological niche. }\end{array}$ & Inference \\
\hline $\begin{array}{c}\text { How do we decide } \\
\text { what to believe about } \\
\text { environmental issues }\end{array}$ & $\begin{array}{c}\text { Is the evidence based on observations. In your } \\
\text { answer, evaluate the source of the evidence } \\
\text { whether it is reputable and unbiased. }\end{array}$ & Evaluation \\
\hline $\begin{array}{c}\text { What will be the } \\
\text { consequences of peak } \\
\text { oil }\end{array}$ & $\begin{array}{c}\text { Will famine in the future be due to rising food } \\
\text { prices? Explain why or why not? }\end{array}$ & Explanation \\
\hline $\begin{array}{c}\text { How are human } \\
\text { activities linked to the } \\
\text { phosphorus and } \\
\text { nitrogen cycles. }\end{array}$ & $\begin{array}{c}\text { Develop a diagram to illustrate the links between } \\
\text { the phosphorous, nitrogen, and carbon cycles. }\end{array}$ & Meta-cognition \\
\hline $\begin{array}{c}\text { Should people eat } \\
\text { lower on the food } \\
\text { chain }\end{array}$ & What is the energy content of 333000 kg of \\
\hline
\end{tabular}


Table 4. t-test Results for new educators' self evaluation

\begin{tabular}{|l|c|c|c|c|}
\hline Performance Index & $\begin{array}{c}\text { Control Group } \\
\text { Base value (\%) }\end{array}$ & $\begin{array}{c}\text { Critical } \\
\text { Thinking Group } \\
(\%)\end{array}$ & Improvement (\%) & $\mathrm{t}$ \\
\hline 1.Observation & 80 & 97 & 21 & 2.7 \\
\hline 2. Interpretation & 79 & 94 & 19 & 2.1 \\
\hline 3. Analysis & 82 & 90 & 10 & 2.9 \\
\hline 4.Inference & 77 & 96 & 25 & 3.3 \\
\hline 5.Evaluation & 79 & 89 & 13 & 3.6 \\
\hline 6.Explanation & 78 & 92 & 18 & 2.5 \\
\hline 7.Meta-cognition & 78 & 85 & 9 & 3.1 \\
\hline Average & 79 & 92 & 17 & 2.9 \\
\hline
\end{tabular}


Table 5. t-test Results for students' evaluation on the new educators' teaching effectiveness

\begin{tabular}{|l|c|c|c|c|}
\hline Performance Index & $\begin{array}{c}\text { Control Group } \\
\text { Base value (\%) }\end{array}$ & $\begin{array}{c}\text { Critical } \\
\text { Thinking Group } \\
(\%)\end{array}$ & Improvement (\%) & $\mathrm{t}$ \\
\hline 1.Observation & 73 & 92 & 26 & 3.3 \\
\hline 2. Interpretation & 71 & 86 & 21 & 2.9 \\
\hline 3. Analysis & 71 & 84 & 18 & 2.7 \\
\hline 4.Inference & 70 & 91 & 30 & 2.3 \\
\hline 5.Evaluation & 74 & 87 & 18 & 3.1 \\
\hline 6.Explanation & 72 & 90 & 25 & 3.4 \\
\hline 7.Meta-cognition & 73 & 79 & 8 & 2.6 \\
\hline Average & 72 & 87 & 21 & 3.1 \\
\hline
\end{tabular}




\section{Appendix $1^{8}$ \\ Critical Thinking Issue \\ Energy Saved by Eating Lower on the Food Chain}

Tom is an average person. He weighs $160 \mathrm{lbs}$. Tom needs to eat equivalent of $600 \mathrm{lbs}$. of frogs per year. The frogs in turn need to eat equivalent of 8 million grasshoppers per year. The grasshoppers in turn need 700,000 lbs. of wheat per year for their survival. If people eat wheat instead of grasshoppers, then 0.7 million pounds of wheat are sufficient to feed 600 people (instead of one person, Tom).

\section{Critical Thinking Questions}

1. $1 \mathrm{~g}$ of completely dried vegetation contains 21 kilojoules $(\mathrm{kJ})$ of energy. Note that wheat has $78 \%$ water. What is the energy content of the 700, $000 \mathrm{lbs}$. of wheat ${ }^{8}$ ? Express the energy content in Joules.

2. As you move down on the food chain the energy content at each lower level increases. Where does the energy lost go? 